IZA DP No. 4293

On the Robustness of Brain Gain Estimates

Michel Beine

Frédéric Docquier

Hillel Rapoport

July 2009 


\title{
On the Robustness of Brain Gain Estimates
}

\author{
Michel Beine \\ University of Luxembourg and CESifo \\ Frédéric Docquier \\ FNRS, IRES, Université Catholique de Louvain \\ and IZA \\ Hillel Rapoport \\ Bar-Ilan University, EQUIPPE (Universités de Lille), \\ Université Catholique de Louvain, CReAM and CEPREMAP
}

\section{Discussion Paper No. 4293 \\ July 2009}

IZA

P.O. Box 7240

53072 Bonn

Germany

Phone: +49-228-3894-0

Fax: +49-228-3894-180

E-mail: iza@iza.org

Any opinions expressed here are those of the author(s) and not those of IZA. Research published in this series may include views on policy, but the institute itself takes no institutional policy positions.

The Institute for the Study of Labor (IZA) in Bonn is a local and virtual international research center and a place of communication between science, politics and business. IZA is an independent nonprofit organization supported by Deutsche Post Foundation. The center is associated with the University of Bonn and offers a stimulating research environment through its international network, workshops and conferences, data service, project support, research visits and doctoral program. IZA engages in (i) original and internationally competitive research in all fields of labor economics, (ii) development of policy concepts, and (iii) dissemination of research results and concepts to the interested public.

IZA Discussion Papers often represent preliminary work and are circulated to encourage discussion. Citation of such a paper should account for its provisional character. A revised version may be available directly from the author. 


\section{ABSTRACT}

\section{On the Robustness of Brain Gain Estimates}

Recent theoretical studies suggest that migration prospects can raise the expected return to human capital and thus foster education investment at home or, in other words, induce a brain gain. In a recent paper (Beine, Docquier and Rapoport, Economic Journal, 2008) we used the Docquier and Marfouk (2006) data set on emigration rates by education level to examine the impact of brain drain migration on gross (pre-migration) human capital formation in developing countries. We found a positive effect of skilled migration prospects on human capital growth in a cross-section of 127 developing countries, with an elasticity of about 5 percent. In this paper we assess the robustness of our results to the use of alternative brain drain measures, definitions of human capital, and functional forms. We find that the results hold using the Beine et al. (2007) alternative brain drain measures controlling for whether migrants acquired their skills in the home or in the host country. We also regress other indicators of human capital investment on skilled migration rates and find a positive effect on youth literacy while the effect on school enrolment depends on the exact specification chosen.

JEL Classification: F22

Keywords: brain drain, brain gain, migration

Corresponding author:

Frédéric Docquier

IRES

Université Catholique de Louvain

3, Place Montesquieu

B-1348 Louvain-La-Neuve

Belgium

E-mail: frederic.docquier@uclouvain.be

\footnotetext{
* We thank the World Bank Migration and Development Program for financial support (P.O Number 7641476).
} 


\section{Introduction}

Starting with Mountford (1997), a recent theoretical literature has suggested that migration prospects can raise the expected return to human capital and thus foster education investment at home or, in other words, induce a brain gain. ${ }^{1}$ To the best of our knowledge, the first paper to investigate this question empirically was our joint paper published in the Journal of Development Economics in 2001. This was a first but imperfect try since we had to use gross migration rates as a proxy measure for the brain drain due to the lack of comparative data on international migration by education levels. In a more recent paper (Beine et al., 2008), we used the Docquier and Marfouk (2006) data set on emigration rates by education level to examine the impact of brain drain migration on gross (pre-migration) human capital formation in developing countries. We found a positive effect of skilled migration prospects on human capital growth in a cross-section of 127 developing countries, with an elasticity of about 5 percent. In this paper we assess the robustness of our results to the use of alternative brain drain measures, definitions of human capital, and functional forms. We find that the results hold using the Beine et al. (2007) alternative brain drain measures controlling for whether migrants acquired their skills in the home or in the host country. We also regress other indicators of human capital investment on skilled migration rates and find a positive effect on youth literacy while the effect on school enrolment depends on the exact specification chosen.

This paper is organized as follows. Section 2 presents the theoretical framework and derives the main testable implications of the analysis. Section 3 summarizes the Docquier and Marfouk (2006) data set, which we supplement with the brain drain estimates computed by Beine et al. (2007), who controlled for immigrants' age of entry as a proxy for whether schooling was acquired in the home or in the host country. The empirical analysis is conducted in Section 4. We first discuss a number of econometric issues and then present the results for the benchmark model (our EJ results) as well as for alternative specifications, human capital measures, and brain drain indicators. Section 5 concludes.

\section{Theoretical and empirical framework}

In this section, we develop a simple theoretical model describing the incentive mechanism related to skilled migration prospects. Then we describe how this model can be empirically tested. ${ }^{2}$

\footnotetext{
${ }^{1}$ See also Vidal (1998), Stark et al. (1998), Docquier and Rapoport (1999), Beine et al. (2001). Using a slightly different perspective, Stark et al. (1997) also elaborated on the possibility of a brain gain associated with a brain drain in a context of imperfect information with return migration. See Docquier and Rapoport (2008) for a comprehensive survey of this literature.

${ }^{2}$ This section is reproduced from our EJ paper.
} 


\subsection{Theoretical background}

Consider a stylized small open developing economy where output is proportional to labor measured in efficiency units ${ }^{3}, Y_{t}=w_{t} L_{t}$. Due to exogenous inter-country productivity differentials, the equilibrium wage rate in this economy, $w_{t}$, is lower than in the developed nations. At birth, individuals are endowed with a given level of human capital normalized to one. They live for two periods, and make two decisions: whether to invest in education during their youth, and whether to migrate in adulthood. There is a unique education program $e$. For an individual opting for education, the number of efficiency units once adult is given by $h>1$ while the cost of education, which is decreasing in personal ability, is denoted by $c$, a variable with cumulative distribution $F(c)$ and density function $f(c)$ defined on $R^{+}$.

Once adult, people can emigrate to a high-wage destination with probability $p$ for skilled workers and $p$ for unskilled workers. As explained in our introduction, selective immigration policies, together with the tendency for migrants to positively self-select out of the general population, explain why emigration rates are much higher among the highly educated and skilled. For example, Docquier and Marfouk's (2006) data, detailed in Section 3 below, reveal that emigration propensities are five to ten times higher for workers with more than twelve years of education than for workers with less than twelve years of education. We will therefore assume that $p>p$. For analytical simplicity, we normalize $\underline{p}$ to zero. Also, in what follows we treat $p$ as exogenous, as if it was the result of a relative quota set by immigration authorities in the destination country independently of the number of potential visa applicants. However, we could equally assume that a given number of visas is attributed, which can be translated into a probability of receiving an entry visa by agents with rational (in which case the adjustment is immediate) ${ }^{4}$ or adaptative (in which case the subjective and objective probabilities only coincide at the steady state) expectations with respect to others' education decisions. ${ }^{5}$

Individuals are assumed to be risk-neutral and maximize lifetime income. There is no intertemporal discounting of income. As explained, unskilled workers are assumed to remain in the home country and therefore earn the domestic wage $w$ in both periods. In contrast, skilled workers have the possibility to migrate to a technologically more advanced country where the wage rate per efficiency unit of human capital is $w^{*}>w$. They earn $w-c$ in the first period and then either $w^{*} h$ if they migrate or $w h$ if they don't. For a given migration probability $p$, the condition for investing in

\footnotetext{
${ }^{3}$ Assuming a constant-returns-to-scale production function with physical capital and labor would give the same outcome provided that physical capital is perfectly mobile across countries. The international interest rate would determine the levels of capital per worker and wages. Output would then be proportional to $L$.

${ }^{4}$ Formally, $p$ can be a decreasing function of $c_{p}(p)$ in (1), defining an implicit solution for $p$.

${ }^{5}$ In the empirical analysis, however, it will be important to assess the exogeneity of the migration probability.
} 
education is therefore:

$$
w_{t}-c+(1-p) w_{t+1} h+p w_{t+1}^{*} h>w_{t}+w_{t+1}
$$

and individuals will opt for education if

$$
c<c_{p, t} \equiv w_{t+1}(h-1)+p h\left(w_{t+1}^{*}-w_{t+1}\right)
$$

Clearly, migration prospects raise the expected return to human capital in the developing country, thus inducing more people to invest in education. The critical threshold $c_{p, t}$ is increasing in the probability of migration and in the wage differential with the destination country. This suggests that the incentive effect of migration will be stronger in poor countries. However, credit constraints on education investments are likely to be more binding in poor countries. To take this into account, we introduce a minimum threshold of first-period consumption, $\mu_{t}$, which must be financed out of first-period earnings. Hence, for any educated individual, it must be the case that $w_{t}-c>\mu_{t}$ or, equivalently, that:

$$
c<c_{l, t} \equiv w_{t}-\mu_{t}
$$

Liquidity constraints are binding if $c_{l, t}<c_{p, t}$, that is, if $w_{t}-w_{t+1}(h-1)-p h\left(w_{t}^{*}-\right.$ $\left.w_{t}\right)<\mu_{t}$. At the steady state (i.e., for $w_{t}=w_{t+1}$ ), the binding liquidity constraints condition may be written as:

$$
w(2-h)-p h\left(w^{*}-w\right)<\mu .
$$

We therefore impose the restriction that $h \in[1,2]$ to allow for the possibility of either binding or non-binding constraints, depending on the value of $w$. It is clear from the last expression that liquidity constraints are more likely to be binding in poor countries (low $w$ ) facing high emigration rates (high $p$ ).

We denote by $H_{a, t}$ and $H_{p, t}$ respectively the gross or ex-ante (i.e., before migration occurs) and the net or ex-post (i.e., once emigration is netted out) proportions of educated in the population, which we take as a measure of the country's human capital level. The proportion of young agents opting for education is given by $H_{a, t}=F\left(c_{t}^{*}\right)$ where $c_{t}^{*}=\operatorname{Min}\left(c_{p, t}, c_{l, t}\right)$ while the proportion of skilled adults remaining in the country is given by:

$$
H_{p, t}=\frac{(1-p) H_{a, t-1}}{1-p H_{a, t-1}}
$$

At the steady state, we have

$$
\frac{\partial H_{p}}{\partial p}=\frac{(1-p) \frac{\partial H_{a}}{\partial p}-H_{a}\left(1-H_{a}\right)}{\left(1-p H_{a}\right)^{2}}
$$

Using the above expression, it appears that: 
- There is a possibility of beneficial brain drain over some ranges of $p$ providing that $\frac{\partial H_{p}}{\partial p}$ is positive at $p=0$. This first requires that $\frac{\partial H_{a}}{\partial p}$ is positive (i.e., there is an incentive effect), which implies that liquidity constraints are not binding in the closed economy;

- At the margin, an increase in the rate of skilled emigration is good for human capital formation if $\frac{\partial H_{p}}{\partial p}$ is positive at the current emigration rate. Again, this first requires that liquidity constraint are not binding, but this time at the current level of $p$;

- Finally, the total or net effect of migration on human capital formation can be obtained by comparing the ex-post (or net) level of human capital with its counterfactual level in the closed economy solution, $H_{p \mid p=0}=H_{a \mid p=0} \equiv \widetilde{H}$. There is a beneficial brain drain if the net effect is positive, that is, if $H_{p}>\widetilde{H}$.

As explained, the realization of these conditions depends on whether liquidity constraints are binding as well as on the ability distribution. For illustrative purposes, let us consider the case of a uniform distribution: $c \rightsquigarrow U[0,1]$ and assume $\mu<w \leq 1$ to avoid corner solutions. With a uniform distribution, $H_{a}=c^{*}=\operatorname{Min}\left(c_{p}, c_{l}\right)$. Starting from a closed economy equilibrium, three configurations arise.

The most pessimistic one occurs when liquidity constraints are binding in the closed economy. In this case, when $w(2-h)<\mu$ (i.e., when the domestic wage rate is low), there can be no incentive effect: $\frac{\partial H_{a}}{\partial p}=0$. Hence, any marginal increase in the skilled migration probability would generate a net loss:

$$
\frac{\partial H_{p}}{\partial p}=\frac{-(w-\mu)(1-w+\mu)]}{(1-p[w-\mu])^{2}}<0
$$

Obviously, in this case the brain drain can only be detrimental $\left(H_{p}<\widetilde{H}\right)$.

An intermediate configuration arises when liquidity constraints are not binding in the closed economy but become binding once migration prospects are introduced. In this case, when $w(2-h)>\mu>w(2-h)-p h\left(w^{*}-w\right)$ (i.e., when the domestic wage rate is not too low and the migration rate is relatively high), a sufficiently small degree of openess can foster ex-post (or net) human capital if $\frac{\partial H_{p}}{\partial p}$ is positive at $p=0$, that is if

$$
h\left(w^{*}-w\right)>w(h-1)[1-w(h-1)]
$$

However, at the current migration rate, a marginal increase in $p$ reduces the proportion of educated remaining in the economy as binding credit constraints do not allow for the incentive effect to operate further $\left(\frac{\partial H_{a}}{\partial p}=0\right)$. The net effect is positive $\left(H_{p}>\widetilde{H}\right)$ if the skilled emigration probability does not exceed the following critical value:

$$
p<\frac{w(2-h)-\mu}{(w-\mu)(2-h)}
$$


The most optimistic case arises when liquidity constraints are never binding, thus allowing for the incentive effect to fully operate. In this case, obtained when $w(2-$ $h)-p h\left(w^{*}-w\right)>\mu$ (i.e., when the domestic wage rate is high enough and the skilled emigration rate is sufficiently low), the condition for a sufficiently small degree of openess to foster net human capital formation is the same as in (4) and the net effect is positive $\left(H_{p}>\widetilde{H}\right)$ when the skilled emigration rate does not exceed the following critical value:

$$
p<\frac{h\left(w^{*}-w\right)-w(h-1)[1-w(h-1)]}{h\left(w^{*}-w\right)[1-w(h-1)]}
$$

Finally, the sign of $\frac{\partial H_{p}}{\partial p}$ evaluated at the current migration rate can be positive or negative depending on the wage differential and on the magnitude of emigration. When $p$ tends to one, clearly, $\frac{\partial H_{p}}{\partial p}$ is more likely to become negative.

On the whole, our simple theoretical model predicts that migration prospects can stimulate the accumulation of human capital in developing countries under certain conditions: first, there must be an incentive effect (or brain gain), and second, the latter must be greater than actual skilled emigration (or brain drain). The incentive effect would seem to be potentially stronger in poor countries but may be limited there if liquidity constraints are binding. It is therefore a priori unclear whether poor or intermediate income countries experience the strongest incentive effects and, consequently, it is also unclear which type of countries gain or lose more from the brain drain. In the rest of this paper, we will focus on the incentive effect.

\subsection{Related empirical model}

To evaluate the incentive hypothesis described theoretically in (1), we use a $\beta$ convergence empirical model and regress the growth rate of the ex-ante stock of human capital (i.e., including emigrants) between 1990 and $2000, \Delta \ln \left(H_{a}\right)$, on a set of explanatory variables:

$$
\begin{aligned}
\Delta \ln \left(H_{a, 90-00}\right) \equiv & \ln \left(H_{a, 00}\right)-\ln \left(H_{a, 90}\right) \\
\Delta \ln \left(H_{a, 90-00}\right)= & a_{0}+a_{1} \cdot \ln \left(H_{a, 90}\right)+a_{2} \cdot \ln \left(p_{90}\right)+a_{3} \cdot D E N S_{90} \\
& +a_{4} \cdot S S A D+a_{5} \cdot L A T D+a_{6} \cdot R M_{90}+\epsilon
\end{aligned}
$$

It is this human capital formation equation, Equation (6), that we estimate econometrically in Section 4.2. Together with the tautological equation defining the change in the ex-ante stock (Equation 5), it forms our benchmark empirical model. In Section 4.3 , we will use non-linear variants by allowing the emigration rate, $\ln \left(p_{90}\right)$, to interact with dummy variables for whether the country's income per capita was lower than a given threshold in 1990. Such non-linear effects are introduced to capture the role of liquidity constraints ${ }^{6}$.

The following explanatory variables enter in the estimation of Equation (6):

\footnotetext{
${ }^{6}$ Tests were also conducted with dummies based on poverty rates.
} 
- The log of the initial level of ex-ante human capital, $\ln \left(H_{a, 90}\right)$, to capture potential catching-up effects. A negative sign for the coefficient $a_{1}$ would indicate convergence in natives' (residents plus emigrants) human capital among the countries sampled.

- The log of the skilled migration rate at the beginning of the period, $\ln \left(p_{90}\right)$, as a proxy for the migration incentives faced by educated individuals. Ideally, the incentive effect of migration on human capital investment should be identified through the impact of migration prospects on expected returns to education. However, these cannot be computed directly as there are no comparative data on education premia in developing countries. Using differences in GNI per capita, on the other hand, raises endogeneity concerns as this variable is strongly correlated with human capital. In our benchmark model, we will thus let aside wage differentials and differences in GNI per capita and use instead $\ln \left(p_{90}\right)$. A positive sign for the coefficient $a_{2}$ indicates that the incentive effect operates (i.e., there is a brain gain).

- The population density in $1990, D E N S_{90}$, as a proxy for the cost of acquiring education. Clearly, education costs depend on a host of factors such as public expenditures on general and higher education, distances to schools, etc. However, public expenditures on education at the beginning of the sample period (in 1990) are statistically very highly correlated in our sample with the initial level of human capital $H_{90}$. This certainly suggests that such expenditures are effective, but the magnitude of the correlation (0.72) precludes any correct joint estimation of the impact of public expenditures and of possible convergence effects. Population density is likely to reduce distances to schools and, therefore, to decrease the opportunity cost of education.

- Workers' remittances as a share of GDP, $R M_{90}$, first because they can relax credit constraints on human capital investment, and second, because in the absence of statistics on return migration, they provide an indirect means of controlling for possible returns in subsequent periods. ${ }^{7}$

- Regional dummies for sub-Saharan Africa $(S S A D)$ and Latin America (LATD).

\footnotetext{
${ }^{7}$ Indeed, preparing one's return is known to be a central motivation to remit and remittances tend to decline over time as migrants become better integrated in the host country, families are reunited and return prospects diminish. See Rapoport and Docquier (2006) for a comprehensive survey of migrants remittances.
} 


\section{Data}

\subsection{Emigration rates by educational attainment (Docquier and Marfouk, 2006)}

Our benchmark empirical analysis is based on the (World Bank sponsored) Docquier and Marfouk (2006) (henceforth DM) dataset. DM collected data on immigration by education level and country of birth from nearly all OECD countries in 1990 and 2000, using the same methodology and definitions as Carrington and Detragiache (1998) but extending their work in a number of ways. First, census, register and survey data reporting immigrants' educational levels and countries of birth were used for 27 OECD countries in 2000 (which account for 98 percent of the OECD immigration stock) and 24 countries in 1990 (91 percent). For the few remaining countries for which census data were not available, existing data by country of birth were splitted across educational levels on the basis of the regional structure or of the OECD average. On this basis, Docquier and Marfouk (2006) obtained reliable emigration rates by education level for 195 emigration countries in 2000 and 174 countries in 1990. As for the Carrington and Detragiache's dataset, South-South migration is not taken into account; however, on the basis of census data collected from selected non-OECD countries, DM estimate that about 90 percent of all highly-skilled migrants live in the OECD area.

The method used by DM is to rely on receiving country $r^{\prime}$ s census or population register to extract information on immigrants country of birth, age, and skill level. Let $M_{t, s}^{r}$ denote the stock of working-age individuals born in a given country, of skill level $s, s=l, m, h$ (for low, medium and high) and living in country $r$ at time $t$. The stock of emigrants from a given country for a given education level, $M_{t, s}=\sum_{r} M_{t, s}^{r}$, is then obtained by summing over receiving countries. Emigration rates by education levels are then obtained by comparing the number of emigrants to the population at origin with similar characteristics, $N_{t, s}$. For each education category, emigration rates are given by

$$
p_{t, s}=\frac{M_{t, s}}{N_{t, s}+M_{t, s}},
$$

and its share among the total native population (residents and emigrants included) by

$$
H_{a, t}=\frac{N_{t, h}+M_{t, h}}{\sum_{s}\left(N_{t, s}+M_{t, s}\right)} .
$$

These steps require collecting data on the size and skill structure of the workingage population in the origin countries. Population data by age are provided by the United Nations. ${ }^{8}$ Data are missing for a small number of countries but can be estimated using the CIA world factbook. ${ }^{9}$ Population data are split across educational

\footnotetext{
${ }^{8}$ See http://esa.un.org/unpp.

${ }^{9}$ See http://www.cia.gov/cia/publications/factbook.
} 
groups using international human capital indicators. The DM data set is based on the Barro and Lee $(1993,2001)$ estimates for most countries. For countries where the Barro and Lee measures are missing, DM transposed the skill structure of the neighboring country with the closest average school enrolment rate.

We measure the emigration rate of skilled workers as the emigration rate among individuals with tertiary education: $p_{t}=p_{t, h}$. As emigration rates are strongly increasing in human capital, we will also assume that the minimal or incompressible emigration rate is the one observed among people with primary education: $\underline{p}_{t}=p_{t, l}$.

\subsection{Brain drain estimates corrected for age of entry (Beine et al, 2007)}

The DM estimates are built according to a broad definition of "skilled immigrants" in that they include all foreign-born workers with tertiary schooling; for example, Mexican-born individuals who arrived in the US at age 5 or 10 and then graduated from US high-education institutions later on are counted as highly-skilled Mexican immigrants. In contrast, Rosenzweig (2005) suggests that only people with homecountry higher education should be considered as skilled immigrants. This must be considered as a lower-bound measure of the brain drain. Indeed, except for those arrived at very young age, most of the immigrants who then acquired host country tertiary education arrived with some level of home country pre-tertiary schooling. In addition, some of them would still have engaged in higher education in the home country in the absence of emigration prospects. ${ }^{10}$

In Beine et al. (2007) we use immigrants' age of entry as a proxy for where education has been acquired and provide alternative measures of the brain drain by defining skilled immigrants as those arrived in the receiving country after age 12, 18 or 22. We use data on age of entry collected in a sample of OECD countries and then econometrically estimate the age-of-entry structure in the remaining host countries. Observations account for 75 percent of the data set and the remaining 25 percent were obtained by econometric estimation. The resulting corrected skilled emigration rates, which can be seen as intermediate bounds to the brain drain estimates, are by construction lower than those computed without age-of-entry restrictions by Docquier and Marfouk (2006), which we take as our upper-bound brain drain measure.

The results for the year 2000 show that on average, 68 percent of the global brain drain is accounted for by emigration of people aged 22 or more upon arrival (the figures are 78 percent and 87 percent for the 18 and 12 year old thresholds, respectively). For some countries there is indeed a substantial difference between the corrected and uncorrected rates, with a minimal ratio between the two equal to 51 percent. Similar results were obtained for the year 1990. The correlation between

\footnotetext{
${ }^{10}$ Besides, some received home-country governments funds to pursue their studies abroad, which also induces a fiscal loss for the origin country.
} 
the corrected and uncorrected rates is very high ${ }^{11}$ and cross-country differences are globally maintained in the corrected data sets. This should a priori mitigate concerns about children migration possibly leading to cross-sectional biases in the brain drain estimates and, consequently, about potential biases in the estimation of the incentive effect of the brain drain using uncorrected data. This will be confirmed empirically in Section 4.5 below.

\subsection{Other data}

Given that we focus on the brain drain impact on developing countries, our sample excludes high-income countries as well as countries from the former USSR, Yugoslavia and Czechoslovakia (for consistency between the 1990 and the 2000 data points), which gives a total sample of 127 developing countries. The data sources for the other RHS variables in equation (6) and the alternative specifications (see below) are as follows:

- Data on $G N I$ and $G D P$ per capita, population size $\left(P O P_{t}\right)$ and population density $\left(D E N S_{t}\right)$, life expectancy at birth $\left(L E_{t}\right)$, workers' remittances $\left(R M_{t}\right)$ and youth literacy rates $\left(L I T_{t}\right)$ are taken from the World Development Indicators (World Bank, 2005). The GNI per capita is measured in US\$, using the Atlas method. The GDP per capita is measured in constant 2000 US\$.

- Data on net school enrolment rates by schooling level $\left(S E_{t}^{L}, L=P, S, T\right.$ for primary, secondary and tertiary schooling) and public education expenditures per student as percent of GDP per capita $\left(E X P_{t}^{L}, L=P, S, T\right)$ were provided by the UNESCO Institute for Statistics (IUS), Montreal.

- Data on racial tensions $(R A C)$ come from the International Country Risk Guide (1984)

- Regional dummies $S S A D$ and $L A T D$ are according to the commonly used World Bank classification

- Dummies based on poverty rates $(P O O R)$ are taken from the United Nations. We use the 1990-2003 average proportion of the population living with less than $\$ 1$ a day.

\section{Results}

Before we carry out the estimations, we first address some specification issues. Then we give the results for the benchmark model and for alternative specifications.

\footnotetext{
${ }^{11}$ The correlation between global (DM) and corrected rates $(12+, 18+$ and $22+)$ are respectively 99.7, 99.3 and 98.7 percent.
} 


\subsection{Econometric issues}

A first important question concerns the exogeneity of the migration rate. When trying to determine the impact of migration on education, one has to control for the reverse effect since, on average, the proportion of educated is likely to affect the rate of skilled migration. This is due to a number of causes. First, as standard neoclassical models would suggest, a larger stock of human capital may reduce the skill premium and thus increase skilled migration incentives through higher international wage differentials. However, a larger stock of human capital may also generate positive externalities on wages through a variety of channels emphasized in new growth and new economic geography models (see Klenow and Rodriguez-Clare, 2005). Second, with an immigration system based on quotas by country (as was the case for the US system until 1965), the higher the supply of skilled workers in the source country, the lower their probability to emigrate.

In an attempt to cope with this endogeneity issue, recent empirical growth analyses (e.g., Barro and Sala-I-Martin, 1995, Hall and Jones, 1999) have been concerned with the use of truly exogenous instruments. In these studies, the following variables have been suggested as candidate instruments for a first-stage migration equation:

- Life expectancy at birth $\left(L E_{90}\right)$, as a proxy for general living conditions;

- The country's population size $\left(P O P_{90}\right)$, as small countries tend to be more open to migration. Also, following the above discussion on immigration quotas, it is clear that if visas are delivered on a country basis they are likely to be more binding in the case of large countries;

- Racial tensions $(R A C)$, a key traditional "push" factor;

- The number of emigrants living in the OECD area at the beginning of the period $(M T)$, to capture the size of the migration network on which prospective emigrants can count on; ${ }^{12}$.

- The GDP per capita of the source country, as a proxy for wage differentials clearly a driving force of migration.

We retain only two out of these five candidate instruments in our first-stage migration equation as we have to eliminate the variables for which there is a strong presumption of a correlation with human capital. This is the case for wage differentials, for obvious reasons, ${ }^{13}$ and for life expectancy, the exogeneity of which is questionable given the fact that longer-lived individuals can enjoy the benefits of education

\footnotetext{
${ }^{12} \mathrm{As}$ is well known, larger networks are associated with lower migration costs (especially information-related ones) and higher expected wages; all else equal, they should act to increase the number of future migrants. See for example Carrington et al. (1996), Munshi (2003), and Kanbur and Rapoport (2005).

${ }^{13} \mathrm{As}$ a crude test, the correlation between wage differentials and human capital levels is indeed higher than 0.5 .
} 
over a longer period of time. We also exclude racial tensions, for both technical and substantive reasons. Technically, their introduction would result in a significant drop in the size of the sample used in the instrumental variable (IV) estimation, which would lower the comparability with the OLS results. ${ }^{14}$ More substantively, it could well be that racial tensions impact on human capital formation, especially if ethnic discrimination is a serious issue. ${ }^{15}$ We are therefore left with two instrumental variables: total population size, and migration stocks at the beginning of the period. At a theoretical level, there is no obvious reason why the demographic size of a country should be correlated to its education level. Likewise, there is no a priori reason why migration networks at destination should impact on human capital formation beyond their effect on migration prospects and incentives (captured by our instrumentation equation). Since we have only one endogeneous explanatory variable, the number of instruments is large enough to test for exogeneity of the retained intruments using a standard overidentification test.

At an empirical level, the validity of our instruments rests on two conditions: the instruments should first be significantly correlated with the migration rate, and the exogeneity condition requires that they should be uncorrelated with the error term in $(6)$.

Equation (7) reports the results of an OLS regression of the migration equation for the full sample on the two selected instruments (t-statistics are reported between brackets):

$$
\begin{aligned}
p & =\underset{(2.24)}{1.20}+\underset{(8.46)}{0.454} \ln (M T)-\underset{(-13.92)}{0.518} \ln (P O P) \\
R^{2} & =0.509 ; \text { Nobs }=127 ; F=97.14
\end{aligned}
$$

The two instruments are significant at the $1 \%$ significance level and are therefore kept throughout the analysis. Interestingly, population size enters with a negative sign; this supports the conjecture mentioned above, according to which immigration restrictions are more binding for larger countries and, in turn, further justifies the assumption that education decisions are taken in a context of uncertainty regarding future migration opportunities, as asssumed in the theoretical model. This is also in line with the general argument that small countries are more open to emigration. Note also that the sign of $\ln (M T)$ is in line with intuition: a higher initial stock of migrants stimulates future emigration. Together, the variables $\ln (M T)$ and $\ln (P O P)$ account for more than $50 \%$ of the migration variability, which is quite satisfactory for a crosssection analysis. A more formal test relies on the value of the $F$ statistics testing

\footnotetext{
${ }^{14}$ More precisely, the sample size falls to 59 countries when racial tensions are added to the set of instruments. We still obtain a positive incentive effect (of a higher magnitude) and conclude in favour of the exogeneity of the three instruments. The first-stage estimation also supports racial tensions as a strong instrument at the $10 \%$ significance level. The results with this specification are available from the authors upon request.

${ }^{15}$ See Tremblay (2001) and Docquier and Rapoport (2003a,b).
} 
the null hypothesis that all coefficients in (7) jointly equal zero. The test reveals that this null hypothesis is clearly rejected, suggesting that the two instruments are strong. Finally, given that we have more instruments than endogeneous variables, a $J$-test of overidentification was also run to assess the exogeneity property of the retained instruments, the p-values of which are reported in the result tables below. For the parcimonious specification, the test supports the exogeneity assumption of the two instruments, thus providing additional confidence that our instruments are indeed uncorrelated with the human capital variable.

\subsection{The benchmark model}

We now turn to the estimation of equation (6). Table 1 reports the estimation results for the full specification and for a more parcimonious model from which insignificant variables such as LATD, DENS90 and REM90 were excluded. Exclusion of the latter variable leads to a significant increase in the number of countries included (from 103 to 127). The results appear to be very robust to the choice of specification and of the estimation technique (OLS and IV). Skilled migration appears to significantly increase gross (or ex-ante, or pre-migration) human capital stocks. The value of the migration coefficient amounts to 0.0545 or 0.0565 for the OLS estimate (depending on whether the constant and the insignificant explanatory variables are included) and is slightly lower (0.0514 in the parcimonious regression) after instrumenting. ${ }^{16}$ Taken literally, this means that doubling the migration propensity of the highly skilled increases gross human capital formation by 5 percent. This is not negligible in countries where the proportion of highly educated typically lies in the 2-8 percent range and higher education significantly increases (by a factor of 5 to 10) one's chances of emigration.

Regarding the other control variables, we find evidence of convergence in human capital levels among the developing countries sampled. Indeed, the coefficient on the lagged human capital stock is negative and significant at the one percent threshold in all specifications. Moreover, in line with the findings of Easterly and Levine (1997), we find that Sub-Saharian countries display poor performances in terms of human capital formation. In contrast, population density and the dummy variable for LatinAmerica do not seem to exert any significant impact and are therefore omitted in the parcimonious specifications. Finally, workers' remittances are also significant and, negative, which is consistent with a moral hazard story but also and maybe more importantly, raises endogeneity concerns. However, since we already instrument migration, instrumenting remittances raises methodological difficulties (see McKenzie, 2006) which are beyond the scope of this paper. In addition, including remittances has almost no effect on the magnitude of the main coefficients while their inclusion

\footnotetext{
${ }^{16}$ The IV results obtained without a constant are not reported here to save space. In this regression, the estimated incentive effect amounts to 0.057 . We obtain similar results with respect to the Hausman test and the over-identification test.
} 
substantially reduces the size of the sample. For all these reasons, we usually leave remittances aside in our parcimonious specifications.

Table 1: Benchmark regressions

\begin{tabular}{|c|c|c|c|c|}
\hline & $\overline{\text { OLS }}$ & OLS & IV & IV \\
\hline Constant & $\begin{array}{l}-0.013 \\
(0.14)\end{array}$ & - & $\begin{array}{l}-0.015 \\
(0.14)\end{array}$ & $\begin{array}{l}-0.131 \\
(1.67)^{*}\end{array}$ \\
\hline Skilled mig rate in $1990(\operatorname{logs})$ & $\begin{array}{c}0.054 \\
(2.03)^{* *}\end{array}$ & $\begin{array}{c}0.057 \\
(2.24)^{* *}\end{array}$ & $\begin{array}{c}0.054 \\
(2.15)^{* *}\end{array}$ & $\begin{array}{c}0.045 \\
(2.14)^{* *}\end{array}$ \\
\hline Stock of HK in $1990(\operatorname{logs})$ & $\begin{array}{c}-0.239 \\
(6.52)^{* * *}\end{array}$ & $\begin{array}{c}-0.232 \\
(7.48) * * *\end{array}$ & $\begin{array}{c}-0.239 \\
(6.70)^{* * *}\end{array}$ & $\begin{array}{c}-0.240 \\
(6.45)^{* * *}\end{array}$ \\
\hline Sub-Saharan African dummy & $\begin{array}{c}-0.450 \\
(4.29)^{* * *}\end{array}$ & $\begin{array}{c}-0.446 \\
(4.40) * * *\end{array}$ & $\begin{array}{c}-0.450 \\
(4.49)^{* * *}\end{array}$ & $\begin{array}{c}-0.349 \\
(4.04)^{* * *}\end{array}$ \\
\hline Latin American dummy & $\begin{array}{l}-0.091 \\
(1.46)\end{array}$ & $\begin{array}{c}-0.103 \\
(2.14)^{* *}\end{array}$ & $\begin{array}{l}-0.090 \\
(1.48)\end{array}$ & - \\
\hline Population density & $\begin{array}{l}-0.000 \\
(1.36)\end{array}$ & & $\begin{array}{l}-0.000 \\
(1.39)\end{array}$ & - \\
\hline Remittances per capita in 1990 & $\begin{array}{c}-0.798 \\
(2.06)^{* *}\end{array}$ & $\begin{array}{c}-0.827 \\
(2.07)^{* *}\end{array}$ & $\begin{array}{c}-0.798 \\
(2.13)^{* *}\end{array}$ & - \\
\hline $\begin{array}{l}\text { F-stat first stage } \\
\text { Hausman }\end{array}$ & - & - & $\begin{array}{c}124.41 \\
0.967\end{array}$ & $\begin{array}{c}162.12 \\
0.954\end{array}$ \\
\hline Observations & 103 & 104 & 103 & 127 \\
\hline R-squared & 0.46 & 0.79 & 0.46 & 0.38 \\
\hline
\end{tabular}

While the overidenfication test supports the exogeneity of the two instruments in the parcimonious specification, the Hausman test does not support the need for accounting for reverse causality. The $p$-values associated with this test for the two specifications considered are indeed above the usual significance levels (see Columns 3 and 4 in Table 1). Regardless of the retained specification and the estimation method, the coefficient of the rate of migration is significantly positive at a 5 percent level. The benchmark elasticity of human capital formation to skilled migration is obtained in column (2) of Table 1. In this best parcimonious specification, we have $a_{2}=5.65$ percent. Using the standard error of the coefficient, we can also provide an interval of confidence at 95 percent for the elasticity. The lower bound for $a_{2}$ is equal to 0.86 percent and the upper bound amounts to 10.44 percent. Hence, the incentive effect is definitely positive.

\subsection{Alternative functional forms}

Our empirical model is based on a particular log-linear specification for the incentive effect. From Equation (6), the parameter $a_{2}$ can be directly interpreted as the 
elasticity of human capital formation to skilled migration prospects. Let us now examine the robustness of the results to the specification. For this purpose, we consider two alternative specifications where the incentive mechanism operates through either $\ln \left(1+p_{90}\right)$ or directly through $p_{90}$ :

$$
\begin{aligned}
\Delta \ln \left(H_{a}\right)= & a_{0}+a_{1} \cdot \ln \left(H_{a, 90}\right)+a_{2} \cdot \ln \left(1+p_{90}\right)+a_{3} \cdot D E N S_{90}+a_{4} \cdot S S A D \\
& +a_{5} \cdot L A T D+a_{6} \cdot R M_{90}+\epsilon \\
\Delta \ln \left(H_{a}\right)= & a_{0}+a_{1} \cdot \ln \left(H_{a, 90}\right)+a_{2} \cdot p_{90}+a_{3} \cdot D E N S_{90}+a_{4} \cdot S S A D \\
& +a_{5} \cdot L A T D+a_{6} \cdot R M_{90}+\epsilon
\end{aligned}
$$

Table 2 gives the results for these alternative functional forms. Column A recalls the results obtained from the baseline model. Columns B1 and B2 give the complete and parcimonious results obtained with the specification (8). The constant is now significant and the controls which were already significant in the benchmark model (i.e., the initial human capital level, the sub-Saharan dummy, the skilled migration rate and the amount of remittances) remain so. As justified above, we eliminate remittances in the parcimonious regression. Clearly, the significance level of the incentive effect becomes much stronger once $\ln \left(1+p_{90}\right)$ is used. However, the coefficient $a_{2}$ can no longer be interpreted as an elasticity and does not allow for an easy interpretation of the magnitude of the effect.

Columns $\mathrm{C} 1$ and $\mathrm{C} 2$ give the complete and parcimonious results obtained with the specification (9). The constant is now significant as are the controls which were already significant in the benchmark model. Again, remittances are left aside in the parcimonious regression. The coefficient on skilled migration as measured by $p_{90}$ is equal to 0.28 . Taken literally, this means that a 10 percentage points increase in skilled migration increases the growth rate of human capital by 2.8 percentage points over a decade.

On the whole, the results with additional functional forms therefore point to a robust relationship between skilled migration prospects and human caiptal formation in origin countries. 
Table 2: Alternative specifications for the incentive effect

\begin{tabular}{l|ccccc}
\hline \hline & $(1)$ & $(2)$ & $(3)$ & $(4)$ & $(5)$ \\
\hline Constant & -0.013 & -0.242 & -0.333 & -0.237 & -0.327 \\
Sk mig rate in $1990(\operatorname{logs})$ & $(0.14)$ & $(2.33)^{* *}$ & $(3.21)^{* * *}$ & $(2.31)^{* *}$ & $(3.18)^{* * *}$ \\
& 0.054 & - & - & - & - \\
1+ Sk mig rate in $1990(\operatorname{logs})$ & $(2.03)^{* *}$ & & & & - \\
Sk mig rate in 1990 & - & 0.434 & 0.391 & - & \\
& & $(2.77)^{* * *}$ & $(3.23)^{* * *}$ & & \\
Stock of HK in 1990 $(\operatorname{logs})$ & - & - & - & 0.307 & 0.278 \\
& & & & $(2.67)^{* * *}$ & $(3.15)^{* * *}$ \\
Sub-Saharan African dummy & -0.239 & -0.247 & -0.248 & -0.248 & -0.250 \\
& $(6.52)^{* * *}$ & $(6.56)^{* * *}$ & $(6.46)^{* * *}$ & $(6.51)^{* * *}$ & $(6.43)^{* * *}$ \\
Latin American dummy & -0.450 & -0.440 & -0.347 & -0.440 & -0.348 \\
Population density & $(4.29)^{* * *}$ & $(4.35)^{* * *}$ & $(4.11)^{* * *}$ & $(4.31)^{* * *}$ & $(4.09)^{* * *}$ \\
& -0.091 & -0.086 & - & -0.081 & - \\
Remittances per capita & $(1.46)$ & $(1.33)$ & & $(1.26)$ & - \\
& -0.000 & -0.000 & - & -0.000 & - \\
\hline Observations & $(1.36)$ & $(1.60)$ & & $(1.58)$ & - \\
R-squared & -0.798 & -0.659 & - & -0.659 & - \\
\hline \hline
\end{tabular}

Robust t statistics in parentheses

* significant at $10 \%$;* significant at $5 \%$; *** significant at $1 \%$

\subsection{Testing for non-linearities}

Until now, the regressions have assumed that the incentive effect of migration on education is homogeneous across countries. However, one may be concerned about possible non-linearities in the relationship between migration prospects and human capital formation at different income levels. We allow for this possibility by interacting the skilled emigration rate in $1990, \ln \left(p_{90}\right)$, with dummy variables for whether the country's income per capita was lower than a given threshold at the beginning of the period, $G N I D_{90}$. We therefore augment the benchmark specification by adding the interaction term $\ln \left(p_{90}\right)$.GNID to the set of explanatory variables of equation (6), where GNID is a dummy variable equal to 1 if country $i$ is a low income country:

$$
\begin{aligned}
\Delta \ln \left(H_{a, 90-00}\right)= & a_{0}+a_{1} \cdot \ln \left(H_{a, 90}\right)+a_{2} \cdot \ln \left(p_{90}\right)+a_{3} \cdot \ln \left(p_{90}\right) \cdot G N I D_{90} \\
& +a_{4} \cdot D E N S_{90}+a_{5} \cdot S S A D+a_{6} \cdot L A T D+a_{7} \cdot R M_{90}+\epsilon
\end{aligned}
$$

A negative sign for the coefficient $a_{3}$ would suggest a weaker incentive effect in poor countries, due maybe to binding credit constraints on education investment or the 
lower expected transferability of human capital in poor country. Obviously, robustness checks imply the use of different possible thresholds. We therefore interact skilled migration rates with a dummy variable for low-income status using three alternative threshold values of the 1990 GNI per head (500, 750 and 900 US\$).

The advantage of this specification is that the correlation between the raw migration rate and the interaction term remains modest, which moderates the statistical effects of collinearity. Table 3 reports the results with this specification. As the Hausman test conducted above tended to confirm the exogeneity of the migration rate, we only present the OLS results for the specification with interaction terms. ${ }^{17}$

On the whole, the results do not provide any evidence of a different impact for the poorest countries. In all regressions, the interaction term $\ln \left(p_{90}\right)$.GNID is insignificant at usual significance levels. Interestingly, the value of the migration coefficient, $\ln \left(p_{90}\right)$, seems unaffected by the inclusion of interaction terms. However, one may be concerned that in the absence of information on income distribution, average income levels may only imperfectly capture the extent of liquidity constraints. In unreported regressions, we also interacted skilled migration with a dummy variable POOR for whether more than $40 \%$ of the country's population live with less than one dollar per day. As with the previous definition, no significant differences were found between poor and richer countries, leading us to conclude to the absence of non-linearities in the skilled migration-human capital formation relationship.

Table 3: Conditional effects

\begin{tabular}{l|ccc}
\hline \hline & $(1)$ & $(2)$ & $(3)$ \\
\hline Constant & -0.187 & -0.176 & -0.178 \\
Skilled mig rate in $1990(\operatorname{logs})$ & $(2.32)^{* *}$ & $(1.91)^{*}$ & $(2.14)^{* *}$ \\
& 0.030 & 0.034 & 0.031 \\
Skilled migr rate* Income dummy & $(2.10)^{* *}$ & $(2.55)^{* *}$ & $(2.39)^{* *}$ \\
& 0.040 & 0.021 & 0.026 \\
Stock of HK in 1990 (logs) & $(1.15)$ & $(0.67)$ & $(0.95)$ \\
& -0.257 & -0.253 & -0.254 \\
Sub-Saharan African dummy & $(6.13)^{* * *}$ & $(5.47)^{* * *}$ & $(5.92)^{* * *}$ \\
& -0.346 & -0.356 & -0.351 \\
Observations & $(4.04)^{* * *}$ & $(4.11)^{* * *}$ & $(4.09)^{* * *}$ \\
R-squared & 128 & 128 & 128 \\
* significant at 10\%; ** significant at 5\%; *** significant at $1 \%$
\end{tabular}

${ }^{17}$ Using the values of $p_{90}$ predicted by the first stage migration regression leads to similar estimates. These results are available upon request. 


\subsection{Alternative measures of migration prospects}

\subsubsection{Controlling for age of entry}

One may be concerned that the positive incentive effect emphasized above is due to a potential mismeasurement of the brain drain. Indeed, the DM estimates count as skilled immigrants all foreign born individuals independently of whether they acquired education in the home or the host country. In reality, some of them migrated at a very young age, benefited from the education systems in the receiving countries, and it is therefore disputable whether they should be considered part of the brain drain from their country of birth. As explained, this may lead to an over-estimation of the intensity of the brain drain as well as to spurious cross-country variation in the brain drain estimates.

To address this issue, we use the alternative measures of the brain drain of Beine et al. (2007), where skilled immigrants are defined as those who immigrated after age 12,18 or 22 . Denoting by $M_{t, s}^{J}$ the number of skilled emigrants who left their country after age $J$, we compute for each sending country alternative skilled emigration rates and human capital indicators as follows:

$$
\begin{aligned}
p_{t, s}^{J} & =\frac{M_{t, s}^{J}}{N_{t, s}+M_{t, s}^{J}} \\
H_{a, t}^{J} & =\frac{N_{t, h}+M_{t, h}^{J}}{\sum_{s}\left(N_{t, s}+M_{t, s}^{J}\right)}
\end{aligned}
$$

We then test models (6) and (8) using these alternatives measures. Table 4 describes the results. It may be seen that the incentive effect is always positive and significant. Recall that the elasticity of human capital formation to skilled migration was 5.65 percent in the benchmark model. As expected, this elasticity decreases as more skilled migrants are excluded according to an age-of-entry criterion. In the parcimonious models, it is equal to 4.2 percent, 4.2 percent and 4.3 percent after excluding migrants who left respectively before ages 12,18 and 22 . Nevertheless, the incentive effect remains positive and highly significant.

Note that the constant is always significant and that the controls which were significant in the benchmark specification (i.e., the initial level of human capital, the sub-Saharan dummy, and the amount of remittances) remain so. The coefficients and the $R^{2}$ are very stable across models. As may be seen from Colums B1 and B2 in Table 4, similar qualitative results are obtained when combining the brain drain estimates controlling for age of entry with the alternative functional form (8) of the incentive effect. Clearly, these results further support the robustness of the incentive mechanism. 
Table 4: Controlling for age of entry (1/2)

\begin{tabular}{|c|c|c|c|c|}
\hline \multicolumn{5}{|l|}{ Excl. migr. arrived before age 12} \\
\hline & (1) & $(2)$ & $(3)$ & $(4)$ \\
\hline Constant & $\begin{array}{l}-0.135 \\
(1.81)^{*}\end{array}$ & $\begin{array}{l}-0.132 \\
(1.73)^{*}\end{array}$ & $\begin{array}{c}-0.332 \\
(3.15)^{* * *}\end{array}$ & $\begin{array}{c}-0.330 \\
(3.21)^{* * *}\end{array}$ \\
\hline Skilled mig rate in $1990(\operatorname{logs})$ & $\begin{array}{c}0.046 \\
(1.90)^{*}\end{array}$ & $\begin{array}{c}0.042 \\
(2.26)^{* *}\end{array}$ & & \\
\hline $1+$ Skilled mig rate in $1990(\operatorname{logs})$ & & & $\begin{array}{c}0.374 \\
(2.87)^{* * *}\end{array}$ & $\begin{array}{c}0.392 \\
(3.23)^{* * *}\end{array}$ \\
\hline Stock of HK in 1990 (logs) & $\begin{array}{c}-0.258 \\
(6.32)^{* * *}\end{array}$ & $\begin{array}{c}-0.239 \\
(6.32)^{* * *}\end{array}$ & $\begin{array}{c}-0.264 \\
(6.40)^{* * *}\end{array}$ & $\begin{array}{c}-0.249 \\
(6.44)^{* * *}\end{array}$ \\
\hline Sub-Saharan African dummy & $\begin{array}{c}-0.439 \\
(4.43)^{* * *}\end{array}$ & $\begin{array}{c}-0.351 \\
(4.02)^{* * *}\end{array}$ & $\begin{array}{c}-0.432 \\
(4.44)^{* * *}\end{array}$ & $\begin{array}{c}-0.349 \\
(4.09)^{* * *}\end{array}$ \\
\hline Remittances per capita in 1990 & $\begin{array}{l}-0.733 \\
(1.88)^{*}\end{array}$ & & $\begin{array}{l}-0.628 \\
(1.67)^{*}\end{array}$ & \\
\hline Observations & 104 & 128 & 104 & 128 \\
\hline R-squared & 0.45 & 0.38 & 0.46 & 0.40 \\
\hline \multicolumn{5}{|l|}{ Excl. migr. arrived before age 18} \\
\hline & (1) & $(2)$ & $(3)$ & (4) \\
\hline Constant & $\begin{array}{l}-0.130 \\
(1.73)^{*}\end{array}$ & $\begin{array}{l}-0.126 \\
(1.65)\end{array}$ & $\begin{array}{c}-0.327 \\
(3.16)^{* * *}\end{array}$ & $\begin{array}{c}-0.326 \\
(3.22)^{* * *}\end{array}$ \\
\hline Skilled mig rate in 1990 (logs) & $\begin{array}{c}0.046 \\
(1.97)^{*}\end{array}$ & $\begin{array}{c}0.042 \\
(2.33)^{* *}\end{array}$ & & \\
\hline $1+$ Skilled mig rate in $1990(\operatorname{logs})$ & & & $\begin{array}{c}0.378 \\
(2.87)^{* * *}\end{array}$ & $\begin{array}{c}0.400 \\
(3.21)^{* * *}\end{array}$ \\
\hline Stock of HK in 1990 (logs) & $\begin{array}{c}-0.257 \\
(6.33)^{* * *}\end{array}$ & $\begin{array}{c}-0.239 \\
(6.33)^{* * *}\end{array}$ & $\begin{array}{c}-0.264 \\
(6.40)^{* * *}\end{array}$ & $\begin{array}{c}-0.249 \\
(6.43)^{* * *}\end{array}$ \\
\hline Sub-Saharan African dummy & $\begin{array}{c}-0.440 \\
(4.43)^{* * *}\end{array}$ & $\begin{array}{c}-0.352 \\
(4.02)^{* * *}\end{array}$ & $\begin{array}{c}-0.434 \\
(4.43)^{* * *}\end{array}$ & $\begin{array}{c}-0.351 \\
(4.09)^{* * *}\end{array}$ \\
\hline Remittances per capita in 1990 & $\begin{array}{l}-0.733 \\
(1.89)^{*}\end{array}$ & & $\begin{array}{l}-0.635 \\
(1.68)^{*}\end{array}$ & \\
\hline Observations & 104 & 128 & 104 & 128 \\
\hline R-squared & 0.45 & 0.38 & 0.46 & 0.40 \\
\hline
\end{tabular}


Table 4: Controlling for age of entry (2/2)

\begin{tabular}{l|cccc}
\hline \hline Excl. migr. arrived before age 22 & \multicolumn{5}{c}{ (1) } & $(2)$ & $(3)$ & $(4)$ \\
\hline Constant & -0.123 & -0.119 & -0.321 & -0.321 \\
& $(1.64)$ & $(1.55)$ & $(3.15)^{* * *}$ & $(3.21)^{* * *}$ \\
Skilled mig rate in $1990(\operatorname{logs})$ & 0.046 & 0.043 & & \\
& $(2.02)^{* *}$ & $(2.40)^{* *}$ & & \\
1+ Skilled mig rate in 1990 (logs) & & & 0.388 & 0.415 \\
& & & $(2.80)^{* * *}$ & $(3.16)^{* * *}$ \\
Stock of HK in 1990 (logs) & -0.257 & -0.239 & -0.263 & -0.248 \\
& $(6.34)^{* * *}$ & $(6.33)^{* * *}$ & $(6.40)^{* * *}$ & $(6.44)^{* * *}$ \\
Sub-Saharan African dummy & -0.440 & -0.352 & -0.435 & -0.351 \\
& $(4.44)^{* * *}$ & $(4.03)^{* * *}$ & $(4.43)^{* * *}$ & $(4.09)^{* * *}$ \\
Remittances per capita in 1990 & -0.730 & & -0.639 & \\
& $(1.89)^{*}$ & & $(1.70)^{*}$ & \\
\hline Observations & 104 & 128 & 104 & 128 \\
R-squared & 0.45 & 0.39 & 0.46 & 0.40 \\
\hline \hline
\end{tabular}

\subsubsection{Ratio of skilled/unskilled emigration rates}

In our theoretical model above, we normalized for analytical convenience the emigration prospects of unskilled workers to zero. However, the theoretical mechanism is based not so much on the absolute propensity of skilled workers to emigrate but on the relative propensity. Indeed, in a setting (as ours) where skilled premia are assumed constant across locations, the incentive to invest in education in a context of migration comes from the increase in the odds of migration for people with sufficient (tertiary) education. This aspect, while in the background of our discussion, has not been incorporated explicitly in our econometric analysis. To analyze the sensitivity of our results to the use of the absolute v. relative skilled emigration propensity, we consider an alternative specification where the incentive mechanism operates through $\ln \left(\frac{p_{90}^{s}}{p_{90}^{u}}\right)$, with $p^{s}$ and $p^{u}$ standing for the emigration rates of skilled and unskilled workers respectively. As can be seen from Table 5 , the results with a relative measure of migration prospects are fairly similar to those obtained with the absolute measure. In particular, our main coefficient of interest and its significance levels are basically unchanged. 
Table 5: Alternative (relative) measure of migration prospects

\begin{tabular}{l|ccc}
\hline \hline & $(1)$ & $(2)$ & $(3)$ \\
\hline Constant & 0.005 & - & - \\
Diff skilled-unskilled mig rates (log) & $(0.04)$ & & \\
& 0.053 & 0.057 & 0.051 \\
Stock of HK in 1990 (logs) & $(1.80)^{*}$ & $(2.05)^{* *}$ & $(2.45)^{* *}$ \\
& -0.236 & -0.225 & -0.205 \\
Sub-Saharan African dummy & $(6.50)^{* * *}$ & $(7.28)^{* * *}$ & $(8.40)^{* * *}$ \\
& -0.455 & -0.413 & -0.321 \\
Latin American dummy & $(4.21)^{* * *}$ & $(4.46)^{* * *}$ & $(4.27)^{* * *}$ \\
& -0.082 & - & - \\
Population density & $(1.30)$ & & - \\
Remittances per capita in 1990 & -0.000 & - & - \\
& $(1.41)$ & & \\
\hline Observations & -0.757 & -0.713 & - \\
R-squared & $(1.93)^{*}$ & $(1.83)^{*}$ & \\
\hline \hline
\end{tabular}

Robust t statistics in parentheses

* significant at $10 \% ;{ }^{* *}$ significant at $5 \% ; * * *$ significant at $1 \%$

\subsection{Alternative measures of human capital investment}

In this section, we test the incentive mechanism when alternative measures of human capital investment are used. In the benchmark model, we used the change in the proportion of tertiary educated natives (residents + emigrants) between 1990 and 2000. The regressions below are based on two other possible measures, namely, school enrolment and youth literacy rates (for the 15 to 24 year olds). The regression models become:

$$
\begin{aligned}
\ln \left(S E_{95}^{L}\right)= & a_{0}+a_{1} \cdot \ln \left(S E_{90}^{L-1}\right)+a_{2} \cdot \ln \left(p_{90}^{L}\right)+a_{4} \cdot \ln \left(E X P_{95}^{L}\right) \\
& +a_{5} \cdot S S A D+a_{6} \cdot L A T D+a_{7} \cdot R M_{90}+\epsilon \\
\ln \left(L I T_{95}\right)= & a_{0}+a_{1} \cdot \ln \left(E X P_{90}^{S}\right)+a_{2} \cdot \ln \left(p_{90}\right)+a_{4} \cdot \ln \left(E X P_{95}^{L}\right) \\
& +a_{5} \cdot S S A D+a_{6} \cdot L A T D+a_{7} \cdot R M_{90}+\epsilon
\end{aligned}
$$

where $S E_{95}^{L}$ is the 1995 net rate of school enrolment at education level $L(L=T, S, P$ for tertiary, secondary and primary education), $S E_{90}^{L-1}$ is the 1990 enrolment rate at schooling level just below $L$ (except for primary education), $E X P_{95}^{L}$ is the amount of public expenditures in US\$ per student at education level $L$, and $L I T_{95}$ is the youth literacy rate in 1995. The variable $p_{90}^{L}$ stands for the emigration rate of individuals who emigrated after graduating in their country (i.e. after age 22 for $L=T$, after age 18 for $L=S$ and after age 12 for $L=P$ ). 
Table 6 describes the results. The left panel of Table 6 gives the results for school enrolment, first with the specification in (11) (in Columns T1, S1 and P1) and then with $\ln \left(1+p_{90}\right)$ instead of $\ln \left(p_{90}\right)$ (in Columns T2, S2 and P2). The right panel of Table 6 describes the results obtained for the regressions using (12) and the same functional forms as above.

Regarding school enrolment, we do not find any evidence of an incentive effect of skilled emigration when using the log-linear specification (11). The coefficient associated to the skilled emigration rate is never significantly different from zero. This is consistent with the results of Faini (2003), who found a depressing but not significant effect of tertiary emigration on domestic enrolment in higher education. However, when we use $\ln \left(1+p_{90}\right)$ instead of $\ln \left(p_{90}\right)$, the effect of skilled migration becomes significant, with a negative impact on tertiary schooling and a positive impact on secondary schooling. Finally, public education expenditures are not significant, except for secondary enrolment. The enrolment rate is strongly determined by the lagged enrolment rate at the lower level. The sub-Saharan dummy is always highly significant.

Regarding literacy rates, however, we find strong evidence of an incentive effect whatever the specification used, with an elasticity of about 4.5 percent.

Coming back to school enrolment, how can we explain that, depending on the specification used, school enrolment rates are either not affected by skilled migration prospects while the other measures of human capital investment are, or that they are negatively affected (for tertiary school enrolment) while the others measures of human capital investment are positively affected? A first explanation could be that school enrolment data raise more measurement problems than human capital stock data as the latter result from an aggregation of flows and are therefore less subject to periodical measurement errors.

A second explanation is suggested by Faini (2003), who attributes his finding of a potentially depressing effect of skilled emigration on tertiary and secondary school enrolment to the choice of would-be migrants to pursue their studies abroad. Our findings are different as they show either no impact (with the $\ln \left(p_{90}\right)$ specification) or a significant incentive effect at the secondary level and a negative effect at the tertiary level (with the $\ln \left(1+p_{90}\right)$ specification). The latter is consistent with a story where skilled migration prospects lead more students to invest in secondary schooling at home to buy and then exercise the option of studying abroad at the upper level, an interpretation we do not want to push too far given the lack of robustness of the results. Note also that while our main measure of human capital formation (the change in the proportion of highly educated among natives) accounts for return migration of skilled migrants, school enrolment indicators do not, which could also go part of the way towards reconciling the two approaches. 


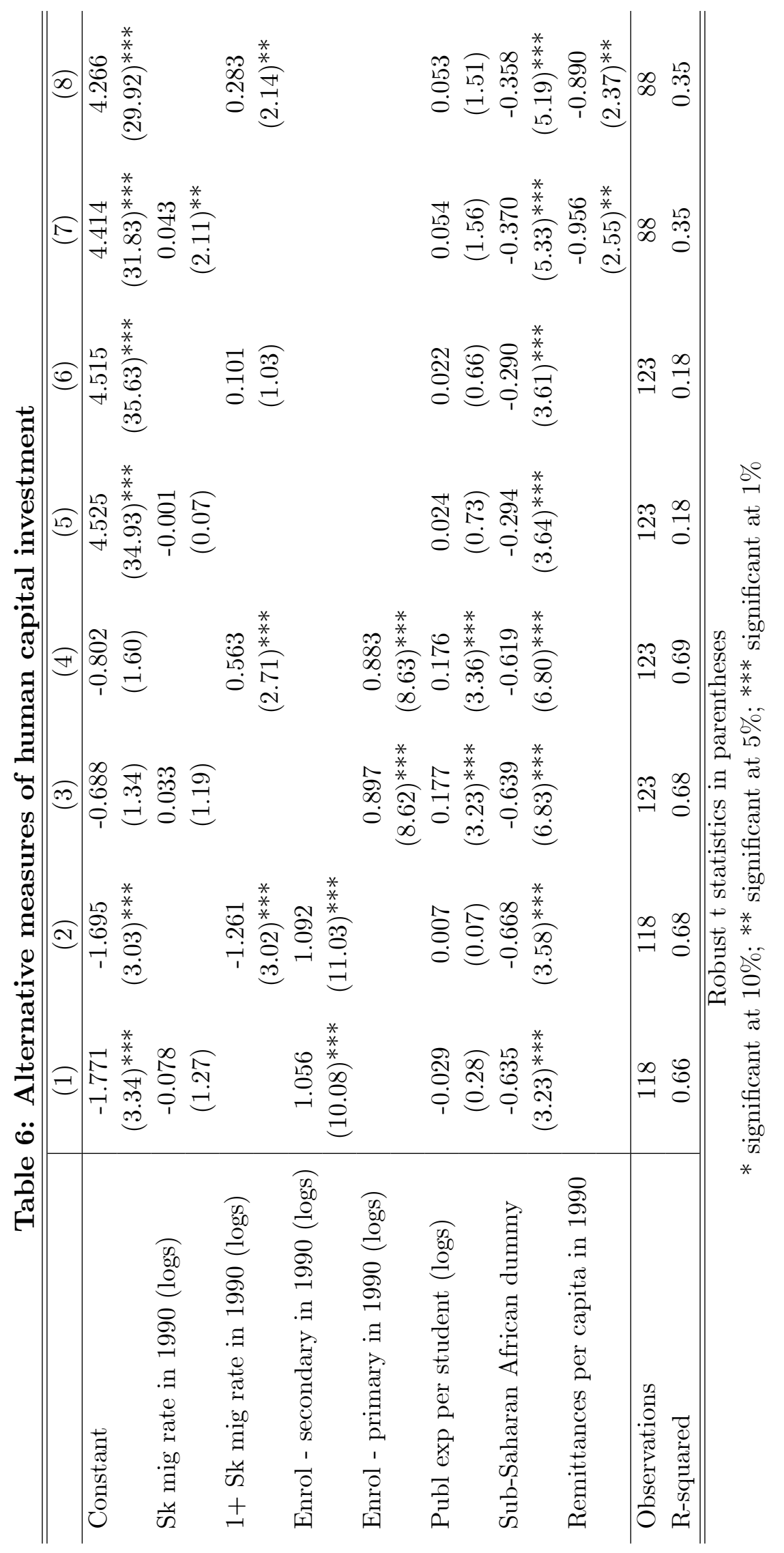


Table 7: Accounting for the age structure of the population

\begin{tabular}{l|cccc}
\hline \hline & $(1)$ & $(2)$ & $(3)$ & $(4)$ \\
\hline Constant & -0.122 & - & - & - \\
Skilled mig rate in 1990 (logs) & $(0.20)$ & & & \\
& 0.054 & 0.056 & 0.055 & 0.057 \\
Stock of HK in 1990 (logs) & $(1.71)^{*}$ & $(2.20)^{* *}$ & $(2.22)^{* *}$ & $(2.24)^{* *}$ \\
& -0.235 & -0.233 & -0.236 & -0.232 \\
Sub-Saharan African dummy & $(6.56)^{* * *}$ & $(6.29)^{* * *}$ & $(7.29)^{* * *}$ & $(7.48)^{* * *}$ \\
Latin American dummy & -0.449 & -0.447 & -0.449 & -0.446 \\
& $(4.08)^{* * *}$ & $(4.30)^{* * *}$ & $(4.26)^{* * *}$ & $(4.40)^{* * *}$ \\
Remittances per capita in 1990 & -0.097 & -0.102 & -0.096 & -0.103 \\
& $(1.48)$ & $(1.54)$ & $(2.05)^{* *}$ & $(2.14)^{* *}$ \\
Population density & -0.828 & -0.811 & -0.802 & -0.827 \\
& $(2.01)^{* *}$ & $(2.06)^{* *}$ & $(2.10)^{* *}$ & $(2.07)^{* *}$ \\
Share of population 15-24 & -0.000 & -0.000 & -0.000 & - \\
Share of population 49-55 & $(1.21)$ & $(1.49)$ & $(1.56)$ & \\
& 0.754 & 0.086 & - & - \\
\hline Observations & $(0.30)$ & $(0.17)$ & & - \\
R-squared & -1.081 & - & - & 104 \\
\hline \hline
\end{tabular}

Robust t statistics in parentheses

* significant at $10 \% ; * *$ significant at $5 \% ; * * *$ significant at $1 \%$

Finally, a third interpretation is that the positive effect on natives' human capital investment emphasized in our benchmark regressions and beyond results from the age distribution of the population in sending countries. Indeed, developing countries are characterized by important turnover rates, with young and better educated workers enterring massively into the labor force. If the turnover rate is for whatever reason higher in countries with high skilled emigration rates, this will induce a spurious mechanism leading to overestimate the strenght of the incentive effect. We address this issue in Table 7 where we control for the share of workers aged 15-24 and 55-64 in the benchmark regression. These demographic shares are never significant and do not distort the results.

\section{Conclusion}

The brain drain has long been viewed as a serious constraint on poor countries development. However recent theoretical literature suggests that migration prospects can raise the expected return to human capital and foster gross (pre-migration) investment in education at home. This paper empirically assesses the robustness and 
magnitude of this incentive mechanism, also referred to in the literature as a "brain gain". We first reproduced our benchmark specification, as appeared in Beine et al. (2008), where we found evidence of a positive effect of skilled migration prospects on human capital investment in a cross-section of 127 developing countries. In that benchmark model, we measure human capital formation by the log variation in the proportion of highly-skilled workers among the native labor force. The elasticity of human capital growth to skilled emigration prospects was found to be in the neighborhood of $5 \%$ and was very stable across specifications and estimation methods (OLS and IV). In this paper we check the robustness of these results and obtain similar qualitative resuts when using alternative brain drain estimates controlling for whether migrants acquired their skills in the home or in the host country and when using a relative (instead of an absolute) measure of migration propensity. We also regressed other indicators of human capital investment on skilled migration rates and found a positive effect on youth literacy while the effect on school enrolment depends on the exact specification used. Notwithstanding the latter finding, which still needs qualification, and within the limits of a cross-sectional analysis, our results point to a robust, positive and sizeable effect of skilled migration prospects on human capital formation in developing countries.

\section{References}

- Barro, R. and J.W. Lee (1993): International measures of schooling years and schooling quality, American Economic Review, Papers and Proceedings, 86, 2: 218-23.

- Barro, Robert J. and Jong-Wha Lee (2001): International Data on Educational Attainment: Updates and Implications, Oxford Economic Papers, 53, 3: 541-63.

- Barro, R. and X. Sala-I-Martin (1995): Economic Growth, New-York: McGraw Hill.

- Beine, M., F. Docquier and H. Rapoport (2001): Brain drain and economic growth: theory and evidence, Journal of Development Economics, 64, 1: 275-89.

- Beine, M., F. Docquier and H. Rapoport (2007): Measuring international skilled migration: a new database controlling for age of entry, World Bank Economic Review, 21, 2: 249-54.

- Beine, M., F. Docquier and H. Rapoport (2008): Brain drain and human capital formation in developing countries: winners and losers, Economic Journal, 118, 528: 631-52.

- Carrington, W.J. and E. Detragiache (1998): How Big is the Brain Drain?, IMF Working Paper, No 98. 
- Carrington, W.J, E. Detragiache, and T. Vishwanath (1996): Migration with endogenous moving costs, American Economic Review, 86, 4: 909-30.

- Docquier, F. and A. Marfouk (2006): International migration by education attainment, 1990-2000; In: C. Ozden and M. Schiff (eds): International migration, brain drain and remittances, New York: McMillan and Palgrave. Chapter 5, pp. 151-99.

- Docquier, F. and H. Rapoport (1999): Fuite des cerveaux et formation de capital humain, Economie Internationale, 78, 3: 63-71.

- Docquier, F. and H. Rapoport (2003a): Ethnic discrimination and the migration of skilled labor, Journal of Development Economics, 70, 1: 159-72.

- Docquier, F. and H. Rapoport (2003b): Endogenous discrimination, migration prospects and the protection of ethnic minorities, Annales d'Economie et de Statistique, 71-72: 79-95.

- Docquier, F. and H. Rapoport (2008): Skilled migration: the perspective of developing countries, in J. Bhagwati and G. Hanson, eds.: "Skilled immigration: problems, prospects and policies", Oxford University Press.

- Easterly, W. and R. Levine (1997): Africa's growth tragedy: policies and ethnic divisions, Quarterly Journal of Economics, 112, 4: 1203-50.

- Faini, R. (2003): Is the brain drain an unmitigated blessing?, UNU-WIDER Discussion Paper No 2003/64, September.

- Hall, R.E. and C.I. Jones (1999): Why do some countries produce so much more output per worker than others?, Quarterly Journal of Economics, 114, 1: 83-116.

- Kanbur, R. and H. Rapoport (2005): Migration selectivity and the evolution of spatial inequality, Journal of Economic Geography, 5, 1: 43-57.

- Klenow, P.J. and A. Rodriguez-Clare (2005): Externalities and growth; in P. Aghion and S. Durlauf, eds.: Handbook of Economic Growth, North Holland. Vol. 1A, Chapter 11, pp. 817-61.

- McKenzie, D. (2006): Beyond remittances: the effects of migration on Mexican households, in C. Ozden and M. Schiff (eds), International Migration, Remittances and the Brain Drain, The World Bank: Washington D.C., pp 123-148.

- Mountford, A. (1997): Can a brain drain be good for growth in the source economy?, Journal of Development Economics, 53, 2: 287-303.

- Munshi, K. (2003): Networks in the modern economy: Mexican migrants in the US labor market, Quarterly Journal of Economics, 118, 2: 549-99. 
- Rapoport, Hillel and Frederic Docquier (2006): The economics of migrants' remittances; in S.C. Kolm and J. Mercier-Ythier, eds.: Handbook of the economics of giving, reciprocity and altruism, Amsterdam: North-Holland. Vol. 2, Chapter 17, pp. 1135-98.

- Rosenzweig, M.R. (2005): Consequences of migration for developing countries, Paper prepared for the UN conference on international migration and development, Population Division.

- Stark, O., C. Helmenstein and A. Prskawetz (1997): A brain gain with a brain drain, Economics Letters, 55: 227-34.

- Stark, Oded, Christian Helmenstein and Alexia Prskawetz (1998): Human capital depletion, human capital formation, and migration: a blessing or a 'curse'?, Economics Letters, 60, 3: 363-7.

- Tremblay, K. (2001): Ethnic conflicts, migration and development, Unpublished PhD dissertation, University of Paris I-Sorbonne.

- Vidal, J.-P. (1998): The effect of emigration on human capital formation, Journal of Population Economics, 11, 4: 589-600.

- World Bank (2005): World Development Indicators, Washington: The World Bank. 